\title{
APLIKASI VISUALISASI DATA SEKOLAH DI KABUPATEN PASURUAN JAWA TIMUR BERBASIS ANDROID
}

\author{
Andy Pramono, S.Kom, M.T. ${ }^{1}$ \\ Betty Dewi Puspasari, S.Kom, M.T. ${ }^{2}$ \\ ${ }^{1}$ Universitas Negeri Malang, Jurusan Seni Desain, Email: radensugih2716@yahoo.com \\ ${ }^{1}$ STT Atlas Nusantara Malang, Program Studi Teknik Informatika, Email: prasari1611@yahoo.com
}

\begin{abstract}
Abstrak: Pada saat ini kebutuhan akan ketersediaan informasi yang cukup akurat sangat dibutuhkan dalam segala bentuk kegiatan atau usaha, baik itu dalam lingkup pemerintahan maupun usaha. Demikian pula dalam hal ketersediaan informasi data non akademik sekolah sangat diperlukan bagi Dinas Pendidikan dan kebudayaan Kabupaten Pasuruan, yang selama ini mengalami kesulitan dalam mengambil kebijakan pengembangan pendidikan di Kabupaten Pasuruan karena kurangnya informasi non akademik sekolah. Penelitian ini merupakan pengembangan dari penelitian sebelumnya yang berbasis web untuk propinsi Kalimantan Timur, penelitian ini akan menghasilkan suatu aplikasi visualisasi pemetaan sekolah Kabupaten Pasuruan yang akan menghasilkan suatu aplikasi yang mampu memberikan informasi mengenai data non akademik sekolah bagi Dinas Pendidikan Kabupaten Pasuruan yang divisualisasikan dalam bentuk pemetaan vektor 2D ini dilaksanakan dalam beberapa tahap melalui tahap pengumpulan data dan analisa, konsep perancangan aplikasi (konsep perancangan meliputi DFD, ER, Desain Interface) dan implementasi dan ujicoba. Hasil dari penelitian ini adalah memberikan alternatif solusi dalam memberikan informasi data non akademik sekolah di Kabupaten Pasuruan Jawa Timur.
\end{abstract}

Kata Kunci: Pemetaan Sekolah, mobile, vektor 2 dimensi

\section{Latar Belakang}

Penerapan sistem informasi mengenai data sekolah saat ini telah mulai dibangun di seluruh Indonesia, namun pada saat ini sistem informasi ini masih bersifat data akademik dari sekolah. Berkaitan data diluar sistem akademik sekolah masih kurang bahkan belum diimplementasikan di seluruh wilayah Indonesia. Padahal sistem informasi diluar sistem akademik sekolah sangat penting bagi pemerintah baik pemerintah nasional maupun pemerintah daerah, adapun sistem informasi non akademik ini lebih ditekankan mengenai SDM, fasilitas dan manajemen sekolah. Sistem informasi non akademik ini sangat penting untuk digunakan sebagai analisa dan evaluasi keadaan suatu sekolah. Keberadaan sistem informasi non akademik seperti ini belum ada di Kabupaten Pasuruan Jawa Timur.

Perkembangan sistem informasi saat ini telah sampai pada saat yang baik sekali dimana suatu sistem informasi dapat dibangun dengan memperhatikan kondisi dan keadaan tempat implementasi suatu sistem informasi. Memperhatikan kondisi georafis Kabupaten Pasuruan yang memiliki luas wilayah $14.493 \mathrm{~km}^{2}$ dengan kondisi berbukit maka perancangan sistem informasi di Kabupaten Pasuruan lebih diarahkan pada sistem informasi berbasis mobile.

Dengan memperhatikan hal tersebut diatas perancangan aplikasi untuk visualisasi pemetaan sekolah ini diarahkan pada siatem informasi web dan mobile yang memungkinkan beberapa daerah dalam wilayah Kabupaten Pasuruan dapat mengakses sistem informasi dimanapun posisi mereka berada.

\section{PETA}

Peta merupakan pengenalan lokasi yang digunakan untuk mengidentifikasi suatu daerah. Peta memiliki berbagai macam bentuk seperti yang dapat kita lihat peta yang sering digunakan sebagai bahan ajar mata pelajaran geografi berupa buku bernama atlas, berisi beberapa Negara di dunia dan kota-kota yang terdapat di dalamnya. Pengertian peta adalah gambaran permukaan bumi pada bidang datar dengan skala tertentu melalui sistem proyeksi (Pengetahuan Peta, Mata Pelajaran Geografi). Menurut Buranda (1985:4) pada hakekatnya peta adalah alat bantu atau alat peraga untuk menyampaikan gagasan-gagasan pada orang lain. Agar hakekat peta sebagai alat peraga membawa manfaat yang sebesar-besarnya maka terdapat beberapa hal yang perlu diperhatikan dalam pembuatan peta sebagai berikut: a. Pencitraan gambar peta jelas dan tidak membingungkan, sehingga pembaca tidak kebingungnan saat membaca. Penambahan legenda, skala, judul yang menunjukan isi dan lokasi daerah yang di gambarkan pada peta memudahkan pembaca atau pengguna, b. Mudah ditangkap pembaca, yaitu dengan dilengkapi simbol, tata warna dan proyeksi yang jelas, c. Peta harus memberikan gambaran yang sebenarnya suatu daerah atau wilayah. Kejelasannya dapat tampak dari penggunaan skala, dan tujuan dari peta tersebut, d.Petadiharapkan bersih dan rapi.

\section{Multimedia Interaktif}

Media interaktif kini banyak menjamur tidak hanya seluruh dunia, ini akibat kecanggihan teknologi informasi yang kian mempercantik diri untuk memenuhi kebutuhan konsumen. Baik dari 
company profile hingga media pembelajaran untuk sekolah dan perguruan tinggi.

Menurut Tay Vaughan (2004:3) multimedia adalah kombinasi dari teks, foto, seni grafis, suara, animasi, dan elemen-elemen video yang dimanipulasi secara digital.

Menurut Sutopo (2002:251) multimedia berhubungan dengan perangkat lunak yang digunakan dalam pengembangan dengan lebih dari satu cara untuk menyampaikan informasi kepada pengguna.

Menurut Murbandono mengartikan bahwa multimedia adalah media massa berdasar computer. Hal ini lah yang menjadi karakter khas dan muatan filosofis dari multimedia di bandingkan dengan semua model media massa lainya. Secara filosofis dapat disimpulkan multimedia adalah medium berdasar computer yang lebih mnegedepankan eksplorasi berkarakter riset dibandingkan performance teknologi demi bisnis.

\section{Sistem Operasi Android}

Pengertian Android sendiri adalah sistem operasi berbasis Linux yang dipergunakan sebagai pengelola sumber daya perangkat keras, baik untuk ponsel, smartphone dan juga PC tablet. Secara umum Android adalah platform yang terbuka bagi para pengembang untuk menciptakan aplikasi mereka sendiri untuk digunakan oleh berbagai piranti bergerak.

Semenjak kehadirannya pada 9 Maret 2009, Android telah hadir dengan versi 1.1, yaitu sistem operasi yang sudah dilengkapi dengan pembaruan estetis pada apalikasinya, seperti jam alrm, voice search, pengiriman pesan dengan Gmail, dan pemberitahuan

email.

Hingga tahun 2012, Android telah berkembang dengan pesat. Dalam kurun 3 tahun Android telah diproduksi dalam versi, dan versi terakhir yang diproduksi disebut sebagai Android versi 4.1 atau Android Jelly Bean.

\section{Karakteristik Media Interaktif berbasis Android}

Media interaktif mobile sebagai media penyampaian informasi atau pesan memiliki beberapa karakteristik sebagai berikut: (1) Teks :teks berfungsi sebagai penjelas tambahan di dalam Media interaktif mobile ini. Di dalam Media interaktif mobile ini teks cenderung berskala medium tapi tidak dalam jumlah banyak, karena teks tidaklah karakteristik yang mendominasi Media interaktif mobile,(2) Ilustrasi: secara umum grafik berarti gambar garis, yang merupakan komponen penting dalam perancangan Media interaktif mobile. Menurut Jefkins (1995:9) salah satu cara untuk menyampaikan informasi secara cepat dan tepat adalah menggunakan kata-kata dan gambar. Maka daripada itu, ilustrasi merupakan hal penting untuk menarik pengguna menggunakan Media interaktif mobile ini.,(3) Animasi:animasi adalah menggerakan obyek 2D yang bergerak agar terlihat hidup seperti berjalan, berbicara, melompat dan lain sebagainya. Sutopo (2002:219) menyimpulkan membuat animasi berarti menggerakan gambar seperti kartun, tulisan dan lain sebagainya.Di dalam perancangan animasi terdapat frame-frame atau tahapan per second untuk menggerakan gambar. setiap frame nya mewakili setiap pergerakan, fungsi frame tersebut untuk memberikan suatu gerakan yang halus dan tidak kaku.,(4) Suara:dalam hal ini suara yang dibutuhkan adalah suara yang mengiringi Media interaktif mobile, dan efek tombol untuk menarik perhatian pengguna., (5) Hubungan Interaktif:hubungan interaktif dalam konteks ini adalah terjadinya timbal balik kontak yang dilakukan, reaksi akibat tercapainya tujuan media yang interaktif. Seperti contoh pengguna menekan tombol untuk melink halaman selanjutnya dan menekan tombol lain untuk memasuki halaman berikutnya. Sutopo (2002:220) menyebutkan bahwa alternative link diperlukan bila pengguna menunjuk pada suatu obyek atau button supaya dapat mengakses program tertentu. Interactive link diperlukan untuk menggabungkan beberapa elemen multimedia sehingga menjadi informasi yang terpadu.

\section{Vektor 2 Dimensi}

Vektor adalah besaran yang memiliki nilai dan arah. Kecepatan, percepatan,gaya, tekanan, momentum dan sebagainya adalah contoh-contoh besaran vektor. Penulisan vektor dengan vektor satuan mempermudah pengertian tentang arah vektor itu.Beberapa vektor dapat dijumlahkan maupun dikalikan. Pada bab ini Kamu akan memperdalam tentang vektor sebagai besaran yang memiliki nilai dan arah. Meliputi vektor dua dimensi dan vektor tiga dimensi.

Orang mengukur jarak adalah menghitung seluruh lintasan gerak yang ditempuh, sedangkan mengukur perpindahan berarti mengukur panjang dari titik awal ke arah titik akhir lintasan. Jadi kalau seorang siswa berlari dari suatu sudut mengelilingi lapangan sepak bola satu kali putaran, berarti Ia menempuh jarak keliling lapangan sepak bola itu, tetapi dikatakan perpindahannya nol. Contoh besaran skalar lainnya adalah panjang, massa, waktu, suhu, kelajuan. perlajuan, usaha, daya sedangkan contoh besaran vektor diantaranya perpindahan, kecepatan, percepatan, gaya, momentum dan sebagainya. Gambar 1 merupakan besaran vektor diantaranya kecepatan angin, 
kecepatan arus air laut yang menggerakkan kapal laut, kecepatan pesawat tempur.

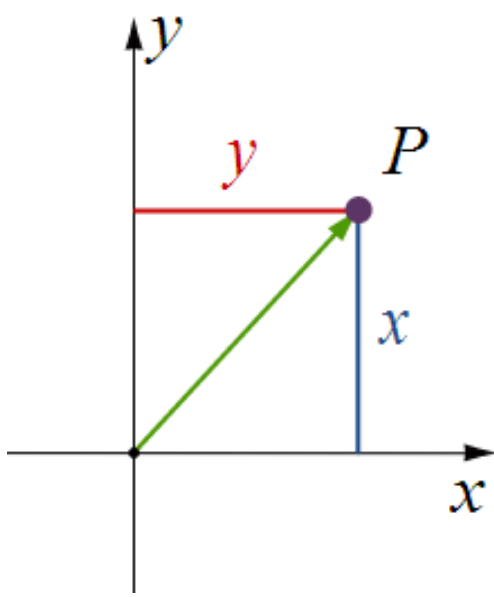

Gambar 1. Vektor 2 Dimensi

Menurut Alonso dan Finn, sebuah vektor dapat digambarkan berupa anak panah atau ruas garis berarah.Panjang anak panah atau ruas garis menyatakan nilai atau besar vektor, sedangkan arah anak, panah menyatakan arah vektor.Notasi besaran vektor dapat dinyatakan dengan huruf besar atau huruf kecil yang diberi tanda panah di atasnya. Misalnya: vektor ab atau $|\mathrm{AB}|$

\section{Metode Penelitian}

Adapun konsep perancangan dari peta Media interaktif mobile ini dapat digambarkan pada gambar 3 dibawah ini

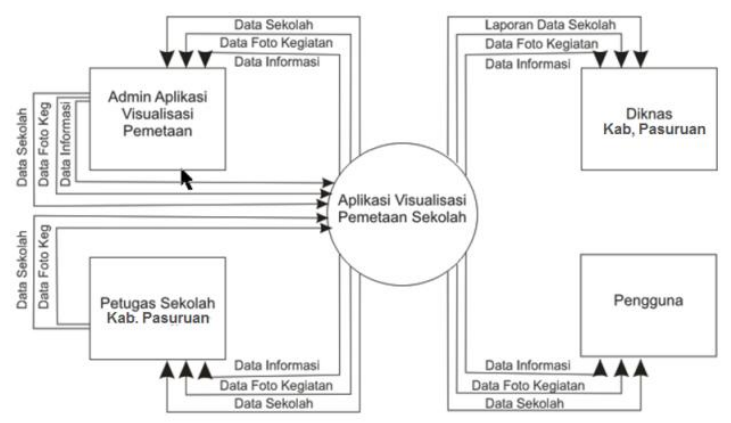

Gambar 2. DFD Level 0 Aplikasi Visualisasi Data Sekolah Kab Pasuruan

Adapun pada perancangan ini diawali dengan pengumpulan data yang meliputi data pustaka dan observasi. Dalam tahap pengumpulan data ini ada beberapa hal yang didapatkan sebagai sumber data untuk membangun aplikasi visualisasi pemetaan sekolah di Kabupaten Pasuruan.

Berdasarkan DFD level 0, dapat kita lihat bahwa aplikasi ini meliputi dari 3 bahasan utama yaitu mengenai 1. Data informasi yang meliputi informasi pengumuman, berita, dan kegiatan yang akan, sedang dan telah dilakukan dilingkungan Dinas Pendidikan dan Kebudayaan Kabupaten Pasuruan. Untuk bahasan data informasi ini yang dapat melakukan input data adalah pihak petugas sekolah dan admin aplikasi visualisasi pemetaan sekolah. Pihak petugas sekolah yang dalam hal ini ditekankan pada pemberian informasi kegiatan yang dilakukan dilingkungan sekolah masingmasing, sedangkan admin dalam hal input data mengenai pengumuman dan berita dilingkungan Dinas Pendidikan dan Kebudayaan Kabupaten Pasuruan. Sedangkan pihak Dinas Pendidikan dan Kebudayaan Kabupaten Pasuruan dan pengguna umum untuk sub Data Informasi ini hanya dapat melihat., 2. Data Foto Kegiatan ini meliputi segala foto yang bersumber dari kegiatan maupun kondisi fasilitas dari masing-masing sekolah. Untuk bahasan data foto kegiatan ini yang dapat melakukan input data adalah pihak petugas sekolah dan admin aplikasi visualisasi pemetaan sekolah. Pihak petugas sekolah yang dalam hal ini ditekankan pada pemberian foto kegiatan dan kondisi fasilitas yang ada dilingkungan sekolah masing-masing, sedangkan admin dalam hal ini merupakan finalisasi dari data yang diinputkan dari pihak petugas sekolah. Sedangkan pihak Dinas Pendidikan dan Kebudayaan Kabupaten Pasuruan dan pengguna umum untuk sub Data Informasi ini hanya dapat melihat., 3. Data Sekolah ini berisi mengenai informasi data sekolah yang bersifat manajemen yang meliputi data sekolah, data siswa, data guru, dan data fasilitas beserta keadaaannya. Untuk bahasan data sekolah ini yang dapat melakukan input data adalah pihak petugas sekolah dan admin aplikasi visualisasi pemetaan sekolah, pihak admin disini lebih bersifat fasilitator yang membantu apabila terjadi masalah dalam hal masukan data dari masing-masing sekolah.

\section{Hasil dan Pembahasan}

Dalam penelitian ini hasil yang dapat dilihat pada desain interface dari aplikasi visualisasi pemetaan sekolah dan tahap uji coba yang dilakukan pada penerapan yang dilakukan terhadap aplikasi visualisasi pemetaan sekolah ini.

\section{Desain Interface Aplikasi visualisasi Pemetaan Sekolah}

Pemetaan ini terdapat pada bagian Data Sekolah dimana konsep visualisasi dilakukan dengan pola penampilan peta Kabupaten Pasuruan secara keseluruhan dari sini pengguna dapat memilih kecamatan yang akan dipilih (dapat dilihat pada gambar 4. Setelah pengguna memilih kecamatan, maka pengguna akan masuk kedalam tampilan pemetaan per kecamatan seperti ditunjukkan dalam 
gambar 5, dimana dalam tampilan ini dapat dibedakan dalam 2 hal yaitu 1.Untuk pengguna hanya dapat melihat informasi mengenai Data sekolah dengan mengklik icon sekolah., 2. Untuk Admin dan Pegawai Sekolah tidak hanya dapat melihat namun juga dapat menambah data sekolah maupun mengedit data sekolah. Dalam hal menginput data ini pihak admin dan pegawai sekolah tidak hanya menginput data sekolah, data siswa, data guru dan data fasilitas saja namun juga menentukan posisi dari sekolah tersebut.

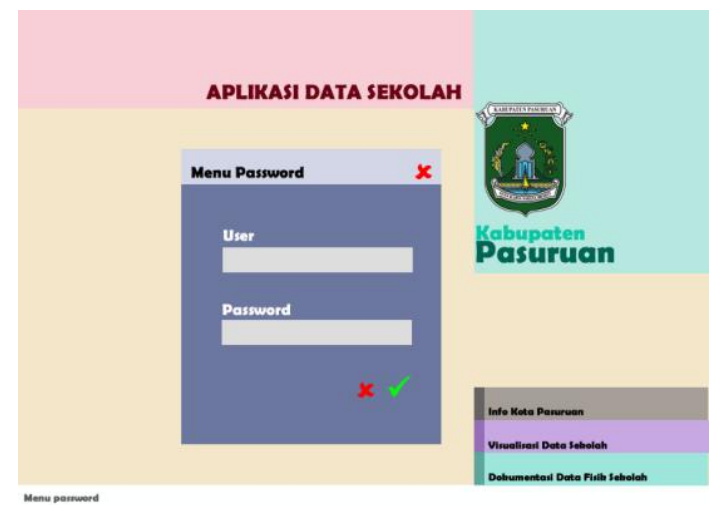

Gambar 3. Tamp ilan Interface Menu Password

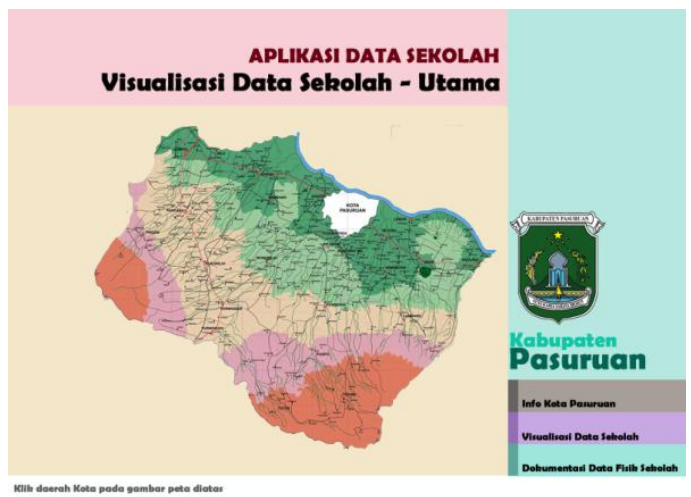

Gambar 4. Tampilan Data Sekolah - Utama

\section{Gaya Desain Media}

Gaya desain yang digunakan pada tampilan peta adalah etnic retro, penggabungan dua unsur yaitu budaya sebagai tanda pengenal dan warnawarna yang mewakili Visualisasi informasi sekolah Kabupaten Pasuruan Jawa Timur. Dua unsur tersebut talah kuat mewakili informasi sekolah dan letak informasi sekolah di Jawa Timur. Motif budaya yang digunakan merupakan motif Jawa Timur minimalis yang terkenal dengan motif berupa akar-akaran sebagai simbolisasi dari hubungan antara manusia dengan alam. Sedangkan warna pastel merupakan perwakilan warna dari kesan natural dari informasi sekolah itu sendiri. Ini juga diwujudkan dalam desain icon dan animasi seperti ditampilkan pada gambar 6. Jenis tipografi yang digunakan adalah Orator Std pada tombol cepat di bagian kanan peta, dan Arial digunakan pada nama peta layanan. Penggunaan font Arial ini dipilih untuk memudahkan pengguna dalam memahami isi dari petadansangat tepat penggunaan nya pada media elektronik atau digital.

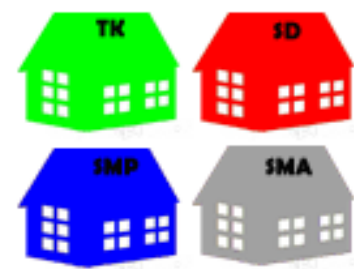

Gambar 5. Tampilan Icon Sekolah

\section{Tahap uji coba Aplikasi visualisasi Data sekolah Kabupaten Pasuruan}

Tahap uji coba dari aplikasi ini dilakukan dengan 2 tahap yaitu tahap uji coba di LAN Universitas Negeri Malang dan tahap uji coba lapangan dilakukan 2 kecamatan di Kabupaten Pasuruan Jawa Timur, yaitu Kecamatan Beji dan Grati. Pada uji coba yang dilakukan di LAN Universitas Negeri Malang, aplikasi diletakkan pada komputer di lab komputer UM, kemudian dilakukan proses uji coba mulai instalasi dan menjalankan aplikasi pada gadget berbasis android, beruda data informasi, data foto kegiatan dan data sekolah. Proses ini dilaksanakan pada 12 titik jaringan di lokasi yang berbeda dengan gadget yang berbeda. Tahap uji coba di lapangan dilakukan di dengan menggunakan 3 Hp Android, uji coba yang dilakukan sama dengan yang dilakukan pada ujicoba 1 yaitu proses uji coba menjalankan aplikasi pada gadget berbasis android, beruda data informasi, data foto kegiatan dan data sekolah. Hasil dari tahap uji coba dapat dilihat pada tabel 1 dibawah ini. Dalam hasil ujicoba secara keseluruhan dapat dikatakan tidak mengalami kendala karena pada 2 tahap ujicoba yang dilakukan hanya pada tahap uji coba di lapangan yang mengalami kendala, hal ini dikarenakan daya Hp yang kurang bagus sehingga mengakibatkan terputusnya proses pada aplikasi visualisasi pemetaan sekolah Kabupaten Pasuruan.

Tabel 1: Tahap uji coba 
Tahap Uji coba

Aplikasi Pemetaan Sekolah Kab.Pasuruan

Android Version

Lokasi : Kampus UM
\begin{tabular}{|l|c|c|c|c|}
\hline \multirow{2}{*}{ Nama Komputer } & \multicolumn{2}{|c|}{ Data Sekolah } & \multirow{2}{*}{ Data Foto } & \multirow{2}{*}{ Data Informasi } \\
\cline { 2 - 3 } & Posisi & Data Info & 100 & 100 \\
\hline IMO Tab Gugun & 100 & 100 & 100 & 100 \\
\hline Andromax U Ali & 100 & 100 & 100 & 100 \\
\hline Andromax I Bagus & 100 & 100 & 100 & 100 \\
\hline Andromax U sari & 100 & 100 & 100 & 100 \\
\hline Andromax USurya & 100 & 100 & 100 & 100 \\
\hline $\begin{array}{l}\text { Sams Galx Tab2 } \\
\text { lis }\end{array}$ & 100 & 100 & 100 & 100 \\
\hline $\begin{array}{l}\text { Samsung G Tab } \\
\text { Dika }\end{array}$ & 100 & 100 & 100 & 100 \\
\hline Andromax U Ulil & 100 & 100 & 100 & 100 \\
\hline Treq Turbo Irma & 100 & 100 & $100^{*}$ & 100 \\
\hline Lenovo Uci & 100 & 100 & 100 & 100 \\
\hline Sams Glxy Grd Ina & 100 & 100 & 100 & 100 \\
\hline $\begin{array}{l}\text { Sams Glxy Ace } \\
\text { Amin }\end{array}$ & 100 & 100 & & \\
\hline
\end{tabular}

Uji Coba di Pasuruan
\begin{tabular}{|l|c|c|c|c|}
\hline \multirow{2}{*}{ Nama Komputer } & \multicolumn{2}{|c|}{ Data Sekolah } & \multirow{2}{*}{ Data Foto } & Data Informasi \\
\cline { 2 - 3 } & Posisi & Data Info & 100 & 100 \\
\hline IMO Tab Gugun & 100 & 100 & 100 & 100 \\
\hline Treq Turbo Irma & 100 & 100 & 100 & 100 \\
\hline $\begin{array}{l}\text { Samsung G Tab } \\
\text { Dika }\end{array}$ & 100 & $100^{*}$ & & \\
\hline
\end{tabular}
-Terdapat masalah pada saat uji coba karena gadget yang habis daya..

\section{Kesimpulan}

Berdasarkan hasil penelitian yang dilakukan pada aplikasi visualisasi pemetaan sekolah Kabupaten Pasuruan Jawa Timur dapat ditarik kesimpulan bahwa penerapan aplikasi visualisasi pemetaan sekolah Kabupaten Pasuruan Jawa Timur dapat dilaksanakan dengan baik dengan tingkat keberhasilan proses 99,5\%, dimana hasil ini didapatkan dari hasil uji coba dimana hasil uji coba untuk tahap Data Sekolah untuk proses penentuan posisi tingkat keberhasilan $100 \%$ sedang proses data info sekolah 99,3\%. Hasil ujicoba untuk Data foto kegiatan tingkat keberhasilan penerapan $98,7 \%$ dan data informasi dengan tingkat keberhasilan $100 \%$.

\section{Daftar Rujukan}

Sutopo, A.H.2002. Analisis dan Desain Berorientasi Objek. Yogyakarta: J\&J Learning Tay, Vaughan. 2004. Multimedia : Making It Work Edisi 6. Yogyakarta : ANDI

Cooper, Alan. About Face 3. The Essentials of Interaction Design, ISBN 978-0470084113, www.newsrider.com, USA, 2008

Hoekman, Robert, Designing the Moment: Web Interface Design Concepts in Action,www.newsrider.com, USA, 2008

Reilly, Designing Interface second edition, ISBN 978-1-449-37390-4, Canada, 